\title{
Prevalence of Bovine Trypanosomosis in Gimbi district, West Wollega, Western Oromiya of Ethiopia
}

\author{
Geremew Batu $^{1}$, Zelalem Abera ${ }^{2}$, Nega Niguse ${ }^{1}$ Aster Tadesse $^{3}$, Moti Wakgari ${ }^{1}$ and Adisu Moti ${ }^{1}$ \\ ${ }^{1}$ West Wollega Livestock and Fisheries Development and Resource office; Gimbi, West Wollega Zone, Oromiya Regional State, Ethiopia \\ ${ }^{2}$ School of Veterinary Medicine, College of Medical and Health Sciences, Wollega University, P.O. Box 395, Nekemte, Ethiopia \\ ${ }^{3}$ Bedelle Regional Veterinary Laboratory Center; Bedelle, Oromiya Regional State, Ethiopia
}

Received: 13 September, 2017; Accepted: 6 October, 2017; Published: 12 October, 2017

*Corresponding author: : Zelalem Abera, Department of Clinical Studies, School of Veterinary Medicine, Wollega University, P.O. Box 395, Nekemte, Ethiopia, E-mail: besha.ab9@gmail.com

\begin{abstract}
A cross-sectional study was carried out from March to May 2014 to determine the prevalence of bovine trypanosomosis in Gimbi district. The method employed during the study was buffy coat technique for parasitological study. Blood samples were collected from ear vein of 445 heads of cattle to assess trypanosome species. The overall prevalence of the disease was $4.9 \%$ and was vary in different peasant associations (PAs) of the study area with $2.7 \%$, $11.8 \%$ and $0 \%$ in Tole, Jogir and Inango Denbeli, respectively. Out of 22 infected animals $63.64 \%$ cattle were found to be infected by T. congolense, (31.8\%) T. vivax, and (4.55\%) mixed parasites (T. congolense and T. vivax).The results showed that, T. congolense was the most prevalent in the study areas and followed by mixed parasites. There was statistically significant difference $(p<0.05)$ in distribution of trypanosoma infection. The prevalence of disease recorded among age groups was $0 \%, 4.7 \%$ and $5.5 \%$ in calves (<3years), youngs (3-9 years) and adults ( $>9$ years), respectively. The results also showed the prevalence between sexes was $4.95 \%$ (male) and $4.93 \%$ (female). The infection rates between different ages and sexes of animals showed no significant difference. The mean PCV value of parasitaemic animals was $22.78 \%$, of aparasitaemic animals was $26.51 \%$ and the overall mean PCV value was $24.65 \%$. Analysis of the mean PCV values of parasitaemic and aparasitaemic animals showed statistically significant difference $(p<0.05)$. The results of the study suggested that trypanosomosis in the area was decreasing. However, due to its impact on the livestock, an appropriate tsetse control methods should be expanded to reach tsetse infested area in a sustainable manner to alleviate the problem of trypanosomosis in the area.
\end{abstract}

Keywords: Bovine; Prevalence; Trypanosomosis; Tsetse Flies; Cattle; Gimbi District;

\section{Introduction}

Trypanosomosis is the most serious veterinary and animal production problem in sub-Saharan Africa and prevents the keeping of ruminants and equines over 10 millions of square kilometers of potentially productive land. Hence, this study is the road map and contribution to the Pan African Tsetse and Trypanosomosis Eradication Campaign agenda [1].
Trypanosomosis is the most important constraint to livestock and mixed crop-livestock farming in tropical Africa. Currently about3 million livestock die every year due to tsetse fly transmitted the disease which covers one third of the continent estimated to be 10 million $\mathrm{km} 2$. A recent study estimated the direct annual cost of the disease to be about 1.34 billion US\$. African livestock producers are administering an estimated 35 million curative and prophylactic treatments annually which costs the producers and the government at least 35 million US\$ [2].

The directlosses from the disease in livestockinclude mortality, morbidity, impaired fertility and the cost of implementing and maintaining tsetse fly and the disease control operations. Indirect losses stem from farmers responses to the perceived risk of the disease, including the reduction and in some cases, the exclusion of livestock from tsetse-infested grazing lands and reduced crop production due to insufficient animal draught power. It is one of the most significant and costly disease in Ethiopia hindering the effort made for food sufficiency [3].

It can be transmitted between the hosts mainly by tsetse flies cyclically, by other biting flies mechanically and by other means of transmission [4, 5]. Trypanosomosis transmitted by tsetse is widespread throughout of the African continent from the southern borders of the Sahara to approximately $20^{\circ}$ south Latitude and is a major factor in holding back the development of these vast areas [6]. Trypanosomosis of domestic livestock covers a great area than of human trypanosomosis. It has a major importance in cattle and, in some regions, in camels, pigs and other domestic animals. The reduced capacity for work animals is also a very important factor where $80 \%$ of the traction power in African Agriculture is provided by animals. Generally there is a great threat of the disease which is a major obstacle to the economic development of the African continent and also reasonable for the incalculable toll of human health [3].

The earliest history of the disease in Ethiopia is in accounts given by explorers and travelers telling of the losses of their transport animals when they had encountered tsetse fly 
belts. According to who in this account of his journey through southern Ethiopia mention the 'Gendi-fly' (Tsetse) attacking his transport animals and causing a disease locally called 'Gendi/ Kosa'(Trypanosomosis) from which many animals died. Six species of trypanosomes are recorded in Ethiopia and the most important trypanosomes, in terms of economic loss in domestic livestock are the tsetse transmitted species: T. congolense, T. viax and $T$. brucei. The closely related T.brucei sub species, $T$. $b$. rhodensiense causes human sleeping sickness. The other trypanosome species of economic importanceare T.evansi of camels and T. equiperdum of horses. T. congolese, T. brucei and T. rhodensiense are highly concentrated in Western, T. vivax in all part but sparse in Eastern part of the country, T. equiperdum in the central and T. evansi highly concentrated in the East, Northeast and Southeast of Ethiopia [3, 7].

Tsetse flies in Ethiopia are confined to the Southern and Western regions between longitude $33^{\circ}$ and $38^{\circ} \mathrm{E}$ and latitude $5^{\circ}$ and $12^{0} \mathrm{~N}$. They infest areas which together amount to $220,000 \mathrm{~km} 2 \mathrm{~s}$. Tsetse infested areas lie in the low lands and also in the river valleys of Abay (Blue Nile), infestation, which currently considered as one of Baro, Akobo, Didessa, Ghibe and Omo [8]. Consequently, new areas are being invaded and settled communities are being continually evicted by the advancing tsetse. These areas include the areas in Upper Didessa Valley, the Northern and Northeastern edges of Lake Abaya in the rift valley, the upper reaches of the Omo-Ghibe and its tributaries.

To date five species of Glossina ( $G$. m. submoristans, $G$ pallidipes, G. tachinoides, G. f.fuscipes and G. longipennis) have been recorded from Ethiopia and except G. longipennis, all of them are widespread and significant economic importance [3]. It is prevalent in two main regions of Ethiopia i.e. the Northwest and the Southwest regions. In most low lying areas, especially in the south west are infested with trypanosomosis deter animal production [9].

Currently, National Tsetse and Trypanosomosis Investigation and Control Center (NTTICC) is working on updating tsetse and trypanosomosis distribution map in Ethiopia, thus wide range of tsetse and trypanosomosis survey were carried out in Abay or Didessa river system [10]. Mixed livestock and crop productions characterize the predominant farming system in the highlands. With livestock playing a vital role in agricultural activities, the provision of animal's draft power is particularly crucial [5].

Tsetse transmitted animal trypanosomosis still remains as one of the largest causes of livestock production losses in Ethiopia [10]. Tsetse flies are estimated to infest over 220,000 KM2 fertile lands in Western, Southwestern and Southern parts of the country. About 15-20 \% of the land believed to be suitable for livestock production is affected by one or two species of the tsetse flies [11]. The effects of trypanosomosis is not only the direct losses resulting from mortality, morbidity, infertility of the infected animals and costs of controlling the disease but also due to indirect losses, which include exclusion of livestock and animal power based crop production from the huge fertile tsetse infested areas [5].
Ethiopia has about 14 million heads of cattle which are exposed to the risk of trypanosomosis. It is not only the loss in meat and milk production of animals recovering from the disease but the great damage caused by the disease is that it has rendered thousands of hectors of land unfit for settlement and cultivation. In addition, some drugs are applied to treat the diseased animals, which are costly. Annual report of National Tsetse and Trypanosomosis Investigation and Control Center indicated that tsetse transmitted animal trypanosomosis is still remain as one of the largest causes of livestock production losses in Ethiopia [10].

In Gimbi district of western Wollega zone of Oromiya regional state, trypanosomosis is one of the most important problems impeding agricultural activity and the production potential of livestock population [12]. No systemic studies have been made on the epidemiology, prevalence and economic significance of bovine trypanosomosisn this area. Therefore, the objectives of the present study were to determine the prevalence of bovine trypanosomosis in the study area.

\section{Materials and Methods}

\section{Study Area}

Across sectional study was conducted from March to May 2014 in three peasant associations (PAs) of Gimbi district, located about $441 \mathrm{~km}$ to the west of Addis Ababa. It is located at $07^{\circ} 02^{\prime} \mathrm{N}$ and $38^{\circ} 28^{\prime} \mathrm{E}$. The area receives an average annual rainfall of $800-$ $1200 \mathrm{~mm}$ and the average annual temperature is $27^{\circ} \mathrm{C}$. The area is covered with a variety of vegetation pattern of cultivated land, bush land, savannah grassland, and patches of dense forests and strips of riverine forests along the riverbanks. The areas have got a number of wild animals, such as African buffaloes, Bush pigs, warthog, bush buck, kudu, hippopotamus, crocodiles, hyena, antelopes and snakes which are claimed to serve as sources of food for the vector of trypanosomes.

\section{Study Population}

The livestock populations that are found in Gimbi district include cattle $(88,784)$, sheep $(34,446)$, goats $(5,306)$, horses $(2)$, mule $(123)$, donkey $(9,448)$ and poultry $(61,702)$. Among these animals, cattle are the dominant species raised in the area as gained from Gimbi district Livestock and Fisheries Development and Resource office. Out of these cattle, a total of 445 cattle were randomly selected from indigenous cattle breed kept under extensive management system.

\section{Study Design and sampling techniques}

Gimbi district was selected purposely based on the extent of the existing problems of trypanosomosis, the complaints of farmers and the level of medium to high tsetse challenge in the area. A cross-sectional study design was employed and three peasant associations were selected based on the veterinarian and farmers reports of the trypanosomosis and tsetse infestation in the district.

The simple random sampling technique was followed, to select the animals to be used for parasitological study in the area. A sample size was determined by the expected prevalence 
of bovine trypanosomosis in the districtwas $12.5 \%$ and the minimum sample size for this cross-sectional study was calculated using the formula by with $95 \%$ confidence level and 5 $\%$ absolute precision. Accordingly, 168 desired sample sizes for the study were calculated $[13,14]$.

$$
\mathrm{n}=\frac{1.96^{2}\left(\mathrm{p}_{\exp }\left(1-\mathrm{p}_{\exp }\right)\right)}{\mathrm{d}^{2}}
$$

Where: $\mathrm{n}=$ required sample size; exp = expected prevalence and $\mathrm{d}=$ desired absolute precision .

Therefore, a total of 445 cattle were sampled randomly from three peasant associations to be involved in this study.

\section{Study Methodology}

Parasitological and hematological techniques were applied for investigation of the parasites [4]. Of all current trypanosomes survey, buffy coat technique (Haematocrit centrifugation technique) is diagnostic technique used in the field and the most sensitive one. Blood samples were obtained by bleeding the marginal ear vein of cattle using a sterile lancet and blood from the ear vein drawn by a heparinized capillary tube at least its 3/4th of volume and sealed at one end with crystal seal. The collected blood centrifuged at $12000 \mathrm{rpm}$ for 5 minutes. The spinning process that separate the $\mathrm{RBC}$ from that of $\mathrm{WBC}$ or $\mathrm{WBC}$ + parasite and plasma according to the specific gravities takes 60,000 rotations $(12,000 \mathrm{rpm} \times 5 \mathrm{~min}$.). When the centrifugation process gets an end, the PCV is red recorded in the survey format or notebook. Animals with PCV reading below 24 were considered as anemic $[15,16]$.
The trypanosomes infection was detected by the method of blood examination at the study site using Buffy-coat dark ground microscopic technique. To identify the species of trypanosomes morphologically, staining technique was used. For positive cases, in Giemsa stained blood smears, the morphology of the species can be distinguished by their size, shape, location and size of kinetoplast, position of nucleus and the attachment and length of flagellum $[17,18]$.Total sample taken, total PCV and prevalence rate were recorded for each particular site, PA or district and finally the overall prevalence rate of the area was calculated as proportion of positives among sampled animals.

\section{Statistical Analysis}

The total prevalence rate was calculated based on the examination positive results by dividing the number of positive results of animals by the total number of animals tested in the area. Appropriate, descriptive and Chi square $\left(\mathrm{X}^{2}\right)$ were calculated. And the pattern of mean packed cell volume (PCV) values were calculated by using t-test formula, the prevalence rates of bovine trypanosomosis between Different ages and sexes of animals and distribution of species of trypanosomes in the areas was compared.

\section{Results \\ Parasitological Findings}

Out of the total of 445 cattleexamined, 22 (4.94\%) of them were positive for different species of parasites (Table 1).The prevalence of the disease was varying from $2.7 \%$ to $11.8 \%$ in some PAs of the Gimbi district and the overall prevalence rate of the area was $4.94 \%\left(X^{2}=5.75 ., p<0.05\right.$ and $\left.\mathrm{CI}=7.96-8.39\right)$.The result showed that there was statistical difference in the study area.

Table 1: Distribution of trypanosome species in different PA of the area

\begin{tabular}{|c|c|c|c|}
\hline \multirow{2}{*}{ Species of Trypanosomes } & \multicolumn{2}{|c|}{ Different sites (PAs) of the Study Area } \\
\hline T. cogolence & Tole & Jogir & Inango Denbeli \\
\hline T. vivax & $4(18.2 \%)$ & $10(45.5 \%)$ & - \\
\hline T. brucei & - & $7(31.8 \%)$ & - \\
\hline Mixed & - & - & - \\
\hline Total & - & $1(4.5 \%)$ & - \\
\hline$X^{2}=27, p=0.000$, CI $=1.27-1.29$ & $\mathbf{4 ( 1 8 . 2 \% )}$ & $\mathbf{1 8 ( 8 1 . 8 \% )}$ & - \\
\hline
\end{tabular}

Prevalence of Bovine Trypanosomosis based on PAs, Sex, Age and Body condition

Prevalence of bovine trypanosomosis was varying from $0 \%$ (in Inango Denbeli PA where no animal was affected) to $11.8 \%$ (in Jogir PA where about 18 animals were positive for trypanosomosis). The result of the study indicated that, the disease was relatively highest prevalent in Jogir as compared to another PAs. Tole and Jogir PAs showed statistically significant association $(\mathrm{p}<0.05)$ with the occurrence of the disease (Table 2$)$.
Age wise prevalence of bovine trypanosomosis was also studied at Gimbi district. Out of the sampled animals, about 13 calves ( $<3$ years) were examined and they were free of the disease (0\%). From 195 examined young animals (3-9 years) about 4.6 \%animals were positive of the disease and among 237 examined adult animals (> 9 years), about $5.5 \%$ animals were positive of trypanosomes. Analysis of age wise prevalence of the disease indicated that the difference in prevalence among the age groups were relatively high in adult than in calves and young groups. Both young and adult animals were infected with $T$. congolense. 
Table 2: Comparison of Prevalence of bovine trypanosomosis in different PAs, ages and sexes

\begin{tabular}{|c|c|c|c|c|c|c|c|}
\hline \multirow{2}{*}{ Variables } & \multirow{2}{*}{ No. of examined } & \multirow{2}{*}{ No. of positive } & \multirow{2}{*}{$\begin{array}{c}\text { Prevalence rates } \\
\text { (\%) }\end{array}$} & \multirow{2}{*}{ P-value } & \multirow{2}{*}{$\mathbf{X}^{2}$} & \multicolumn{2}{|c|}{$95 \%$ CI } \\
\hline & & & & & & Lower & Upper \\
\hline \multicolumn{8}{|l|}{ PA } \\
\hline Tole & 147 & 4 & 2.7 & 0 & 2.58 & 7.96 & 8.39 \\
\hline Jogir & 152 & 18 & 11.8 & 0.002 & 5.75 & 3.18 & 15.3 \\
\hline I/Denbeli & 146 & 0 & 0 & - & - & - & - \\
\hline \multicolumn{8}{|l|}{ Sex } \\
\hline Male & 242 & 12 & & & & & \\
\hline Female & 203 & 10 & & & & & \\
\hline \multicolumn{8}{|l|}{ Age } \\
\hline$<3$ years & 14 & 0 & 0 & 0.997 & & 0.76 & 0.97 \\
\hline 3-9 years & 193 & 9 & & 0.027 & 15.8 & 1.38 & 180.9 \\
\hline$>9$ years & 238 & 13 & & & & & \\
\hline \multicolumn{8}{|l|}{ Body condition } \\
\hline Poor & 201 & 11 & 5.5 & 0.009 & 0.03 & 1.002 & 1.41 \\
\hline Medium & 155 & 9 & 5.8 & 0.16 & 0.32 & 0.07 & 1.6 \\
\hline Good & 89 & 2 & 2.3 & - & - & - & - \\
\hline \multicolumn{8}{|l|}{ PCV } \\
\hline Anaemic & 35 & 17 & & 0 & 76.5 & 25.4 & 230.6 \\
\hline Non-anaemic & 410 & 5 & & & & & \\
\hline Total & 445 & 22 & & & & & \\
\hline
\end{tabular}

But, the obtained result indicates that there was no statistically significant difference in prevalence of bovine trypanosomosis among age groups of animals ( $p>0.05$ ) (Table 2).

The prevalence of bovine trypanosomosis between female and male animals was studied. From a total of 445 cattle randomly selected and examined animals in three PAs, 242 of them were male (54.4\%), from which 12 animals were positives of trypanosomes (4.95\%), while 203 of them were female (45.6 $\%$ ) in which 10 animals were positives of trypanosomes (4.93 $\%)$ as indicated in the following Table 2 . However, there was no statistically significant difference ( $p>0.05$ ) between the two sexes of animals.

Prevalence of bovine trypanosomosis among body condition was studied in the area. From a total of 445 cattle randomly selected and examined animals in three PAs, 201 of them were poor body condition (45.2\%), from which 11 animals were positives of trypanosomes (5.5\%), while 155 of them were medium body condition (34.8\%) in which 9 animals were positives of trypanosomes (5.8\%) and 89 of them were good body condition (20\%) in which $2.25 \%$ animals were positives of trypanosomes and significantly associated $(\mathrm{P}<0.05)$ with the body condition score as indicated in the following Table 2 .

The prevalence of bovine trypanosomosis between female and male animals was studied. From a total of 445 cattle randomly selected and examined animals in three PAs, 242 of them were male $(54.4 \%)$, from which 12 animals were positives of trypanosomes (4.95\%), while 203 of them were female (45.6 $\%$ ) in which 10 animals were positives of trypanosomes (4.93 $\%$ ) as indicated in the following Table 2 . However, there was no statistically significant difference $(p>0.05)$ between the two sexes of animals.

Prevalence of bovine trypanosomosis among body condition was studied in the area. From a total of 445 cattle randomly selected and examined animals in three PAs, 201 of them were poor body condition (45.2\%), from which 11 animals were positives of trypanosomes (5.5\%), while 155 of them were medium body condition (34.8\%) in which 9 animals were positives of trypanosomes (5.8\%) and 89 of them were good body condition (20\%) in which $2.25 \%$ animals were positives of trypanosomes and significantly associated $(\mathrm{P}<0.05)$ with the body condition score as indicated in the following Table 2.

\section{Hematological Findings}

Out of the examined animals, 22 of them were positive and their mean PCV was $24.6 \%$ with an interval of $22.78 \%$ (Lower) to $26.51 \%$ (Higher) and 423 of them were free of disease. From the obtained results of mean PCV values, there was statistically significant difference between infected and non-infected animals, Table $-2\left(\mathrm{X}^{2}=76.5, \mathrm{p}<0.05\right.$ and $\left.\mathrm{CI}=25.4-230.6\right)$. 


\section{Distribution of the species of trypanosomes}

During the study, T. congolense, T. vivax, and some mixed parasites (T. congolense and T. vivax) were detected. Out of 22 infected animals $63.64 \%$ cattle were found to be infected by T. congolense, $31.8 \%$, T.vivax, and $4.5 \%$ mixed parasites (T. congolense and T. vivax) (Table 2). The results showed that, $T$. congolense was highly detected in all PAs followed by T. vivax and there was statistically significant difference $\left(X^{2}=27, p=0.000\right.$, $\mathrm{CI}=1.27-1.29$ ) in distribution between species of trypanosomes.

\section{Discussion}

The study was conducted from March to May 2014 in three peasant associations (PAs) of Gimbi district of western Wollega zone, Oromiya regional state to determine the prevalence of bovine trypanosomosis and to assess the distribution and apparent density of its vectors in the study area.

The overall prevalence of trypanosomosis investigated in this study area was $4.9 \%$ which can be considered as less prevalence due to less vector density which resulted from fly control. The result is virtually similar with the report of who observed 5.43\% prevalence of the disease in Mandura District, Northwest Ethiopia, with the overall prevalence of $5.3 \%$ in Haro Tatessa settlement areaof Upper Dedessa Valley, Illubabor Zone, who reported 6.25 $\%$ prevalence of trypanosomosis in Bako Tibe district of West Shoa and Gobu Seyo districts of East Wollega Zone, 6.86\% of the disease was also recorded in Lalo Kile District, Kelem Wollega Zone, Western Ethiopia [19, 20, 21, 22].

The result of the current study was lower than the reports of disease from different parts of Ethiopia which includes 17.2 $\%$ in Metekel and $17.5 \%$ in the Upper Didessa of tsetse infested regions $[23,24]$. It was also comparatively lower than the prevalence of the disease reported from Gimbi- district during the dry season $10.1 \%$ and rainy season 15 and the prevalence of trypanosomosis $16.9 \%$ in Sayo Nole district conducted by [13, 25].The result of current finding was also far apart from $25 \%$ prevalence recorded in Gawo Dale district and $29 \%$ prevalence done along the escarpment of the Upper Didessa Valley [10, 26]. A hope full reduction of trypanosomosis at Gimbi district is because of the presence of considerable suppression of flies' population by the use of insecticide impregnated targets, spot on application of deltametrin $1 \%$ and prophylactic treatment of livestock undertaken in the area.

From purposively selected district, three peasant associations (PAs) such as Tole, Jogir and Inango Dembeli were randomly selected for trypanosomes survey. During this study, different species of trypanosoma parasites such as T. cogolence (63.6\%), T. vivax (31.8\%) and Mixed (4.5\%) were detected.

We have made an effort to assess the prevalence of bovine trypanosomosis between sexes of animals. From a total of 445 cattle randomly selected and examined animals in three PAs, 242 of them were male (54.4\%), from which 12 animals were positives of trypanosomes (4.95\%), while 203 of them were female (45.6 $\%$ ) in which 10 animals were positives of trypanosomes (4.93\%) as indicated in the following Table 2.The trypanosome infection in female animals was almost similar with male animals; this shows that both male and female cattle were equally susceptible to trypanosomosis. The obtained result of this study showed that there was no statistically significant difference $(p>0.05)$ in infection rates between male and female cattle.

This result coincides with the results of previous studies that reported absence of significant difference in susceptibility between the two sexes $[27,28]$. And also this result is in line with the previous results of who obtained no significant difference in susceptibility between the two sexes $[20,27,29,30]$. But, different researchers were reported that higher prevalence was observed in male cattle than in female $[23,24]$. This shows that, unlike female, the number of male animals is not constant due to the farmers sold the male animals at frequency of 2-3 months after purchased. And also the higher infection rate in males compared to females may be attributed to stress factors related to work where male animals are used for drought purpose and they have to walk long distance in areas where there is a high risk of tsetse challenge.

Analysis of age wise prevalence of the disease was conducted among age groups of animals at the study area. During this study, about 13 calves ( $<3$ years) were examined and they were free of the disease ( $0 \%$ ), but about $4.6 \%$ and $5.5 \%$ animals with age of 3-9 (Young) and >9 (Adult) years were positive of trypanosomosis. This is due to the calves don't go down to the valley floor during the dry season in search of pasture, where the tsetse occupies during this season and young animals are also naturally protected to some extent by maternal antibodies. But, the result indicated that a little difference in prevalence among the age groups were relatively high in adult than in calves and young groups with the absence of statistically significant difference in prevalence of the disease among age groups of animals ( $\mathrm{p}>0.05)$ (Table 2).

This finding is agreed with the works in animals with greater 9 years of age were highly infected $6 \%$ when compared with those between 3-9 years of age $4.5 \%$ [20]. Although this finding is in agreement with the previous report of in which higher prevalence of trypanosome infection was recorded in older animals [31]. This could be associated to the fact that older animals travel long distance for feed and to serve for draught power as well as for harvesting crops and this may pose them to high tsetse fly challenge. There was no statistically significant difference between age groups. Prevalence of the disease was low as compared to that of older which may be due to restricted grazing of young animals near homestead where there are less number of tsetse flies [32].

Prevalence of bovine trypanosomosis among body condition (poor, medium and good) was studied in the area. From a total of 445 cattle randomly selected and examined animals in three PAs, $45.2 \%, 34.8 \%$ and $20 \%$ of them were poor, medium and good body conditioned animals, respectively. Out of these examined animals with different body conditions, $5.5 \%, 5.8 \%$ and $2.3 \%$ of them were positives of trypanosomes for poor, medium and good body conditioned animals, respectively. And the finding showed statistically significant difference in prevalence of the disease among body condition of animals $(\mathrm{p}<0.05)$ (Table 2$)$. 
The result of this finding is in line with the report of who stated that, there is a significant difference $(p<0.05)$ in trypanosome infection rate among body condition of animals [33]. And the result was disagreement with a study who stated that, the prevalence of the disease is high in good body conditioned animals [34]. The infection rate in Medium body conditioned animals was slightly higher than other body conditioned animals (5.8). This is not in agreement with the report of who recorded higher Trypanosome infection rate in poor body conditioned animals than in good and medium ones [35, 36, 37]. This might be attributed to poor body condition animals that are immuno-suppressed and stressed status [36]. The present study in terms of trypanosome species is agreed with that of the dominant trypanosome species in the Abay Basin was T. congolense (66.1\%) followed by T. vivax $(20.8$ $\%$ [38].

Also we have tried to detect distribution of the species of trypanosomes like T. congolense, T. vivax, and some mixed parasites (T. congolense and T. vivax).T. congolense was the dominant species with a proportion of $(63.6 \%)$ and followed by T. vivax $(31.8 \%)$ and T. vivax and T. congolense mixed infection (4.6\%). Analysis of the study shows the presence of statistically significant difference $(\mathrm{X} 2=27, \mathrm{p}<0.000, \mathrm{CI}=1.27-1.29)$ in distribution between species of trypanosomes. This was due to the presence of tsetse-flies of the study areas.

The result of this finding was similar with the report of same disease in Goro district of the south Ethiopia in which the positive cases were due to T. congolense (58.75\%) [39].This result was in agreement with the previous work that stated the predominance of T. congolense infection in cattle as compared to T. vivax which may be due to the development of better immune response to $T$. vivax by the infected animal [23]. In addition, it was reported that the dominant trypanosomes species in upper Didessa of tsetse infested regions was T. congolense [24, 40]. The result was less than with the finding in the Lalo Kile district $75 \%$ reported by, 66.17\% in Southern Rift Valley, 71.8\% in the Gawo Dale district and $72.3 \%$ in Gawo Dale District and $84 \%$ in Ghibe by [22, 40, $41,42]$. But, comparatively it was higher than other studies in southern Ethiopia $37 \%$ by, $58.5 \%$ in tsetse infested areas of the country $[41,43]$.

This high ratio of T. congolense may also suggest that the major cyclical vectors or Glossina species (G. m. submorsitance, G. tachinoides and others) are more efficient transmitters of $T$. congolese than T. vivax in East Africa [44]. The use of drugs may be another factor, which could depress the incidence of $T$. vivax. In East Africa, T. vivax is generally less virulent than T. congolense and consequently cattle developed tolerance to the former more easily than to the latter [45]. Therefore, the chance of detection of T. congolense in peripheral blood of infected animals is higher than the other group. Additionally, the predominance of $T$. congolense infection in cattle may be also due to the high number of serodems of T. congolense as compared to T. vivax and the development of better immune response to T. vivax in the infected animal [46].
So, the predominance of $T$. congolense over T. vivax to prevalence of Glossina (G. m. submorsitans and G. tachinoides) in an area is similar to the previous study, since the transmission of $T$. congolense is mainly cyclical, requiring the prevalence of tsetse flies, where as the transmission of $T$. vivax more readily transmitted mechanically by vectors other than tsetse flies. In the present study there was statistical difference $(p<0.05)$ in the prevalence of trypanosoma infection in the study sites. These might be even the areas are close to each other there is a bit difference climatic and agro ecological condition. The occurrence of trypanosomosis frequently corresponds with the fly density (occurrence of the vectors) which is in turn dependent on those climatic factors as temperature, humidity and vegetation coverage of the area $[46,47]$.

A mixed infection of trypanosomes due to $T$. vivax and $T$. Congolese (4.55\%) was detected during this study.This result signifies that trypanosomosis is still an important constraints in livestock production and productivity. Other researcher also reported $60.7 \%$ T. congulence followed by T. vivax $19.4 \%$. T. congulence mixed infection 19 \%, T.vivax $9.3 \%$, $4.6 \%$ T. brucei were reported from Asosa district, western Ethiopia [48]. T. congulence/T. brucei $7.1 \%$ and T. brucei/ T. vivax $7.1 \%$ in Kaduna central abattoir, Nigeria [49]. This difference could be due to the variation in the ecosystems of the study locations that supported proliferation of both the tsetse and biting flies and regular application of prophylactic treatment in some study PAs.

According to PCV the animals were classified as anemic and non-anemic (Normal) and animals with PCV less than 24\% were considered to be anaemic $[16,50,51]$. Anemia was considered to be an important clinical sign and/or indicator of trypanosomosis and the reduced performance of infected animals $[52,53]$.

During this study an effort was also made to indicate the difference between mean PCV values of parasitaemic and aparasitaemic cattle in the area. Out of 22 animals were positive in which their mean PCV value was $22.78 \%$ and 423 of them were free of disease and their mean PCV value was $26.51 \%$. In cattle, the normal range of mean PCV value was 24-46 and in Gimbi district about 95.1\% (Having greater than $24 \%$ PCV value) were aparasitaemic cattle and the only $4.9 \%$ cattle were parasetamic (Having less than $24 \%$ value) by using a microhematocrit centrifuge technique to recorded PCV value of animals [54]. In line with this, the overall mean PCV value recorded during this study was $24.65 \%$.

According to $60 \%$ of T.vivax infected cattle in the high land showed anemia below a PCV value of $20 \%$ compared to $50 \%$ of T. congolense and T. vivax infected cattle in the lowland. It is known that the development of anemia was the most reliable indicator of the progress of the trypanosome infection but it can also be assumed that numerous concurrent diseases and nutritional factors interfere within anemia development $[3,55$, 56]. Even though it is assumed as such, PCV values are reliable indicator of anemia. Statistical analyses of the results showed that there was significant difference $(\mathrm{p}<0.05)$ in mean PCV values of infected and non-infected animals. Similar trends of mean 
PCV values were reported by other researches $[23,57,24]$. The results by indicated the mean PCV values of $16.7 \%$ and $28.0 \%$ in North Omo Zone; reported $21.65 \%$ and $25.54 \%$ in southwest Ethiopia; reported $20.22 \%$ and $27.23 \%$ in East Wollega Zone, recorded $18.8 \%$ and $24.8 \%$ in Nono district of Oromiya region for parasitaemic and aparasitaemic cattle, recorded $20.80 \%$ and 25.65\% in Harotatessa Settlement Area of Upper Dedessa Valley, Illubabor Zone, respectively $[20,58,59,60]$.

In fact the difference in mean PCV between parasitaemic and aparasitaemic cattle indicated that trypanosomosis may be involved in adversely lowering the PCV values of infected animals. parasitaemic cattle had generally lower mean PCV than the corresponding aparasitaemic cattle. Though, there is appearing of parasitological negative cattle within the PCV values of less than the threshold value. This may be due to inadequacy of detection method as or delayed recovery of anaemic situation after current treatment with trypanocidal drugs and may be other blood parasites infection, malnutrition associated with long draught in the areas [61]. While the occurrences of positive animals with PCV greater than or equal to $25 \%$ might be thought of recent infection of animals.

\section{Conclusion and Recommendations}

Trypanosomosis is a very important disease that causes economic loss in the livestock industry. The overall prevalence of bovine trypanosomosis in Gimbi district was $4.9 \%$; which indicates the decreasing status of the disease and still needs attention. There was $(\mathrm{P}<0.05)$ a statistical significant difference in prevalence of bovine trypanosomosis between Kebeles and PCV scores. The current situation may get not worse as the prevention and control of trypanosomosis is practicing in the area and that is limiting the vector and also chemotherapy. So, the following recommendations were forwarded:

1.Designing and implementation of control strategies of trypanosomosis focusing integrated approach (vector control and chemotherapy) should be continuing in the studied areas.

2.The farmers in the area should be trained on how to control the vectors of the parasites and the disease properly,

3.Expanding an appropriate tsetse control methods (Spot-on and insecticide impregnated targets) to reach tsetse infested area in a sustainable manner,

4.Giving attention to reinvasion of the reclaimed area to effective utilizing the control efforts.

\section{Acknowledgment}

We are grateful to the Bedelle Regional Veterinary Laboratory center and its entire staff member for financial and technical support during this study and giving fed back to the zone and district.

\section{References}

1. WHO. The Pan African Tsetse and Trypanosomosis Eradication Campaign (PATTEC). Plan action. 2001

2. Holmes $\mathrm{PH}, \mathrm{M}$ Eisler, S Geerts. Current chemotherapy of animal trypanosomiasis. In: Maudlin I, Holmes P.H. and Miles M.A. (eds). The Trypanosomiases. CABI, UK. 2004;431- 444.

3. Getachew A. Trypanosomosis in Ethiopia, Addis Ababa University. faculty of veterinary medicine. Bishoftu. 2005;18-20.

4. Uilenberge G. A field guide for diagnosis, treatment and prevention of African animal trypanosomosis. Adopted from the original edition by Boyt W.P. FAO, Rome. 1998;43-135.

5. Awoke K. Mariam. Study of trypanosomosis and its vectors in Humbo and Merab Woredas. EVA Journal. 2000;4(1):61.

6. WHO. Expert committee in trypanosomosis (First Report) Geneva. 1962:6-18.

7. Donaldson Smith A. Through unknown African countries Edward Arnold, London and John Wilson and Co. Cambridge, U.S.A. 1985.

8. Langridge W P. A tsetse and trypanosomosis survey of Ethiopia. Addis Ababa Ethiopia. Ministry of Overseas Development of British and Ministry. 1976.

9. Getachew Abebe JB, Malone, AR Thompson. Geospatial forecast model for tsetse transmitted animal trypanosomosis in Ethiopia. Ethiopia J. Sci. 2004;27(1):1-8.

10. NTTICC. National Tsetse and Trypanosomosis Investigation and Control Center. Report for the Period 7th June 2003- 6th July 2004. Bedelle. 2004:1.

11. NTTICC. National Tsetse and Trypanosomosis Investigation and Control Center. Report for the period 7th July 2001 to 6th July 2002. Bedelle. 2002:3.

12. Abebe G. Trypanosomosis in Ethiopia. Ethio, J. Bio. Sci. 2005;4:75121.

13. Degneh BT, Efrem H, Yacob T, Ashenafi, Hagos, K. Asoke. Department of Pathology and parasitology. Faculty of Veterinary Medicine, AAU. Debre Zeit. Ethiopia. 2007.

14. Thrusfield M. Veterinary Epidemiology. 3rded. UK, Black well science Ltd. 2005;233-250.

15. Urquhart GM, J Armour, JL Duncan, AM Dunnand, FW Jennings. Veterinary Parasitology. Blackwell science, Oxford. 1992;209-253.

16. Office Internationale des. Epizooties (OIE). Trypanosomiasis (tsetse- transmitted): TerrestrialManual. Office Internationaledes Epizooties (OIE). Paris. France. 2008:654.

17. Losos JG. Infectious tropical disease of domestic animals. 1986:938.

18. FAO. Report of Preparatory Assistance Mission to Ethiopia. Food and Agriculture Organization of the United Nations Programme for the Control of African Animal Trypanosomosis and Related Development. FAO. Rome. 1984. 
19. Lelisa K, Damena D, Kedir M, Feyera T. Prevalence of Bovine Trypanosomosis and Apparent Density of Tsetse and other Biting flies in Mandura district, Northwest,Ethiopia. Journal of Vet Scie and Techn. 2015;6:229. doi:10.4172/2157-7579.1000229

20. Zelalem Abera, Feyesa Regass. Prevalence of Bovine Trypanosomosis in Harotatessa Settlement Area of Upper Dedessa Valley, Illubabor Zone, Southwestern Ethiopia.Wollega University, School of Veterinary Medicine, Nekemte, Ethiopia. Acta Parasitologica Globalis. 2015;6 (3):220-230.

21. Zelalem A, Merga F, Tadele K, Girma K, Tesfaye M. Prevalence of Bovine Trypanosomosis in Bako Tibe District of West Shoa and Gobu Seyo Districts of East Wollega Zone, Ethiopia. European Journal of Biological Sciences. 2014;6(3):71-80. doi0: 10.5829/ idosi.ejbs.2014.6.03.85219

22. Efrem D, Bashatu F, Bacha B, Addisalem H, Misgana D. Prevalence of Bovine Trypanosomosis in LaloKile district, KelemWollega Zone, Oromia regional state, Western Ethiopia. Acta Parasitologica Globalis. 2013;4:34-40.

23. Afewerk Y. Field investigation on the appearance of drug resistant population of trypanosomes in Metekel District, North-West Ethiopia, MSc thesis, Addis Ababa University and Freie Universtat Berlin, Faculty of Veterinary Medicine, Ethiopia. 1998

24. Tewelde N. Study on the occurrence of drug resistant trypanosomes in cattle in the farming in tsetse control areas (FITCA) project in western Ethiopia, MSc thesis AAU, FVM, Debre Zeit, Ethiopia. 2001: 1-98.

25. Bedas KK. Prevalence of Bovine Trypanosomosis and Apparent Density of Tsetse Flies in Sayonole District Western Oromia, Ethiopia. Veterinary Drug and Animal Feed Administration and Control Authority, Ministry of Agriculture, Addis Ababa, Ethiopia Journal of Veterinary Science \& Technology, ISSN: 2157-7579. 2015;6:254.

26. NTTICC. National Tsetse and Trypanosomiasis Investigation and Control Centre, (NTTICC), Annual Report, Bedelle, Ethiopia. 1998.

27. Getachew T. Prevalence of bovine trypanosomosis in two districts of western Gojjam province. DVM Thesis AAU, FVM, Debre Zeit, Ethiopia. 1993.

28. Basaznew B, W Kebede, Mersha Ch. Occurrence and Identification of Bovine Trypanosomosis in Genji District, Western Ethiopia, Department of Veterinary Paraclinical Studies, Faculty of Veterinary Medicine, University of Gondar, Ethiopia. Acta Parasitologica Globalis. 2012;3(3):38-42. doi: 10.5829/idosi.apg.2012.3.3.66220

29. Tefera S. Prevalence of bovine trypanosomosis in Arbaminch districts. DVM Thesis, AAU, FVM, Debre Zeit, Ethiopia. 1994

30. Wellde BT, Hockmeyer WT, Koyatch LM. Immunity in bovine to Trypanosoma congolense induced by selfcure or chemotherapy. In Losos G. and Chounad A. pathogenesity of trypanosomosis. 1979.
31. Cherenet T, Sani RA, Speybroeck N, Panandam JM, Nadzr S, Van den Bossche P. A comparative longitudinal study of bovine trypanosomiasis in tsetse-free and tsetse-infestedzones of the Amhara Region, northwest Ethiopia. Vet. Parasitol. 2006;140(34):251-258.

32. Catley A. Learning about Liei, Participatory diagnosis of the chronicwasting problem in cattle in southern Sudan, the publications of Participatory Approaches to Veterinary Epidemiology (PAVE) Project. 2000.

33. Girma K, Meseret T, Tilahun Z, Haimanot D, Firew L, Tadele K, et al. Prevalence of Bovine Trypanosomosis, its Vector Density and Distribution in and Around Arbaminch, Gamogofa Zone, Ethiopia. Wollega University, School of Veterinary Medicine, Nekemte, Ethiopia. Acta Parasitologica Globalis. 2014;5(3):169-176. doi: 10.5829/idosi.apg.2014.5.3.859

34. Mussa A. Prevalence of Bovine Trypanosomosis in Goro wereda, Southwest Ethiopia. DVM Thesis, FVM, AAU, Debre Zeit. 2002.

35. Feyissa B, Samson A, Mihreteab B. Bovine. Trypanosomiasis in Selected Villages of Humbo District, Southern Ethiopia. Glob. Veterinaria. 2011;7(2):192-198.

36. Teka W, Terefa D, Wondimu A. Prevalence study of bovine trypanosomiasis and tsetse density in selected villages of Arbaminch, Ethiopia. J. Vet. Med. Anim. Health. 2012;4(3):36-41.

37. Ayana M, Tesfaheywet Z, Getnet F. A cross-sectional study on the prevalence bovine trypanosomiasis in Amhara region, Northwest Ethiopia. Livestock Res. Rural Dev. 2012;24 (8).

38. Nigatu SD. Epidemiology of bovine trypanosomosis in the Abbay Basin areas of Northwest Ethiopia. Msc thesis, FVM, AAU. Debre Zeit, Ethiopia. 2004.

39. Abiy M. Prevalence of Bovine Trypanosomosis in Goroworeda, southwest Ethiopia. DVM Thesis Abstract, Debre Zeit. 2002:344.

40. Muturi KS, Msangi S, Munstermann S, Clausen P, Getachew A, Getachew T, et al. Trypanosomosis risk assessment in selected sites of the southern rift valley of Ethiopia. In: International Scientific Council for Trypanosomosis Research and Control (ISCTRC). Proceedings of the 25 meeting held in Mombasa, Kenya. OAU/STRC Publication. 2000:12.

41. Rowlands G J, Mulatu W, Authie E, d Ieteren GDM, Leak SGA, Nagda SM et al. Epidemiology of bovine trypanosomiasis in the Ghibe Valley, southwest Ethiopia. Factors associated with variation in the trypanosome prevalence, incidence of new infections and prevalence of recurrent infections .Acta Trop. 1993;53:135-150.

42. Waktole TE. Studies on bovinetrypanosomosis and therapeutic efficacy of selected trypanocidal drugs in Birbir valley of Gawo-Dalle district, West Oromia, MSc Thesis FVM, AAU. Debre Zeit, Ethiopia. 2008. 
43. Abebe G, Jobre Y. Trypanosomiasis: a threat to cattle production in Ethiopia .Rev. Med. Vet. . 1996;147(12): 897-902.

44. Langridge WP. A tsetse and trypanosomosis survey of Ethiopia. Addis Ababa Ethiopia, Ministry of Overseas Development of British and Ministry. 1976.

45. Donaldson Smith A. Through unknown African countries Edward Arnold, London and John Wilson and Co, Cambridge, U.S.A. 1985.

46. Leak SGA. Tsetse Biology and Ecology Their Role in the Epidemiology and Control of Trypanosomosis. CABI publishing in association with the ILRI. 1999;70(4):172-176.

47. Abebayehu T, Hadgu E, Mekbib B, Abebe R, Mekuria S. Mechanically Transmitted bovinetrypanosomosis in Tselemty Woreda, Western Tigray, Northern Ethiopia. Agricultural Journal. 2011;6:10-13.

48. Mulaw S, Addis M and Fromsa M. Study on the Prevalence of Major Trypanosomes affecting Bovine inTsetse Infested Asosa District of Benishangul Gumuz Regional State, Western Ethiopia. Global Vet. 2011;7(4):330-336.

49. Samdi SM, Fajinmi AO, Kalejaye JO, Wayo B, Haruna MK, Yarnap JE, et al. Prevalence of Trypanosomosis in Cattle at Slaughter in Kaduna Central Abattior in Nigeria. Asian J. Anim. Sci. 2011;5(2):162-165.

50. Van den Bossche P, Rowlands GJ. The relationship between the parasitological prevalence of trypanosome infections in cattle and helped average packed cell volume. Acta Trop.2001;78(2):168-170.

51. Marcotty T, Simukoko H, Berkvens D, Vercruyss J, Praet N, Van den Dossche P. Evaluating the use of packedcell volume as indicator oftrypanosomal infections in cattle ineastern Zambia. Preventive Veterinary Medicine. 2008;87(3-4):288-300.

52. Radoostitis OM, Gay CC, Hinch Cliff KW, Constable PD. Disease associated withTrypanosomosomes. In: Veterinary Medicine, Text book of disease of cattle, horses, pigs and goats10thed. Elsevier, UK 2007;1531-1554
53. Trail JCM, Ieteren GDM, Murray M, Ordner G, Yangari G, Maille JC, et al. Measurements of trypanotolerance criteria and their effect onreproductive performance of N'Dama cattle. Veterinary Parasitology. 1993;45(3-4):241-255.

54. Blood DC, Radostitis OM, Henderson JA. Diseases caused by protozoa. A text book of the diseases of cattle, pigs, goats and horses. 7 ed. Oxford: ELBS. 1989:1012-1015.

55. Getachew A, Yilma J. Trypanosomosis: A threat to cattle production in Ethiopia. Revvue Med. Vet. 1996;147(12):897-902.

56. ILRAD. Annual Report of the International Lab. For research on Annual Disease. Livestock production of tsetse affected areas of Africa.1988.

57. Muturi KS. Epidemiology of bovine trypanosomosis in selected sites of the Southern Rift valley of Ethiopia. MSc thesis, FVM, AAU. Debre Zeit, Ethiopia. 1999.

58. Feyisa R, Getachew A. Current epidemiological situation of bovine trypanosomosis in Limu Shay tsetse controlled area of Upper Didessa valley. MSc thesis, FVM, AAU. Debre Zeit, Ethiopia. 2009;13(2):19-33.

59. Takele S. Epidemiology of bovine trypanosomosis in three selected sites of the newly established settlement areas of Sassiga district, in East Wollega Zone, Oromia National Regional State, Western Ethiopia. MSc thesis, FVM, AAU. Debre Zeit, Ethiopia. 2006:1-87.

60. Tekle T. Epidemiology of bovine trypanosomosis in the newly established settlement area of Nono district, southwest Ethiopia. MSc thesis, Addis Ababa University, Faculty of Veterinary Medicine, Debre-Zeit, Ethiopia. 2007: 1-75.

61. Murray M, Murray PK, McIntyre WIM. An improved parasitological technique for the diagnosis of African trypanosomosis. Transactions of the Royal Society of Tropical Medicine and Hygiene. 1977;71(4):325-326. 